\title{
Live strong and prosper: the importance of skeletal muscle strength for healthy ageing
}

\author{
Michael McLeod · Leigh Breen • D. Lee Hamilton • Andrew Philp
}

Received: 27 August 2015/Accepted: 22 December 2015/Published online: 20 January 2016

(C) The Author(s) 2016. This article is published with open access at Springerlink.com

\begin{abstract}
Due to improved health care, diet and infrastructure in developed countries, since 1840 life expectancy has increased by approximately 2 years per decade. Accordingly, by 2050, a quarter of Europe's population will be over 65 years, representing a $10 \%$ rise in half a century. With this rapid rise comes an increased prevalence of diseases of ageing and associated healthcare expenditure. To address the health consequences of global ageing, research in model systems (worms, flies and mice) has indicated that reducing the rate of organ growth, via reductions in protein synthetic rates, has multi-organ health benefits that collectively lead to improvements in lifespan. In contrast, human pre-clinical, clinical and large cohort prospective studies demonstrate that ageing leads to anabolic (i.e. growth) impairments in skeletal muscle, which in turn leads to reductions in muscle mass and strength, factors directly associated with mortality rates in the elderly. As such, increasing
\end{abstract}

M. McLeod · L. Breen · A. Philp ( $\varangle)$

MRC-ARUK Centre for Musculoskeletal Ageing

Research, University of Birmingham,

Birmingham B15 2TT, UK

e-mail: a.philp@bham.ac.uk

M. McLeod · L. Breen · A. Philp

School of Sport, Exercise and Rehabilitation Sciences,

University of Birmingham, Birmingham B15 2TT, UK

D. L. Hamilton

School of Sport, University of Stirling, Stirling, UK muscle protein synthesis via exercise or protein-based nutrition maintains a strong, healthy muscle mass, which in turn leads to improved health, independence and functionality. The aim of this review is to critique current literature relating to the maintenance of muscle mass across lifespan and discuss whether maintaining or reducing protein synthesis is the most logical approach to support musculoskeletal function and by extension healthy human ageing.

Keywords Skeletal muscle $\cdot$ Strength $\cdot$ Health . Protein synthesis · Physiology · Protein metabolism

\section{Introduction}

The percentage of the global population above 65,85 and 100 years is predicted to increase by 188,551 and $1004 \%$ respectively by 2050 (The United Nations; World Population Prospects: http://esa.un.org/unpd/ wpp/). As a consequence, globally, there is a notable increase in the prevalence of 'diseases of ageing', such as sarcopenia, recently been defined by the European Working Group on Sarcopenia in Older People (EWGSOP) as a 'syndrome characterised by progressive and generalised loss of skeletal muscle mass and strength with the risk of adverse outcomes such as physical disability, poor quality of life and death' (Baumgartner et al. 1998; Cruz-Jentoft et al. 2010; Rosenberg 1989). This onset of sarcopenia is 
fundamentally important for health as skeletal muscle in a healthy adult accounts for approximately $40 \%$ of total body mass (Janssen et al. 2000). In addition to its primary tasks of maintaining posture, breathing and locomotion, skeletal muscle also represents an important nutrient store and metabolic regulator (Wolfe 2006). During ageing, approximately $30 \%$ of an individual's peak muscle mass is lost by the age of 80 , and this loss is exacerbated by physical inactivity and poor nutrition (Janssen et al. 2000; Topinkova 2008). This decline in skeletal muscle metabolism and function should not be underestimated, as in the UK alone, complications arising from falls in the elderly (with an association to frailty) are estimated to cost the National Health Service $£ 1.7$ billion annually (www. ageuk.org.uk).

\section{The effect of ageing on human health}

Ageing is characterized by widespread reduction in the reserve capacity of the body's major organs (Topinkova 2008). Of critical importance for lifespan is the reduction in cardiac output (Lambert and Evans 2005), which together with reduced lung function (Taylor and Johnson 2010), decreased skeletal muscle oxidative capacity (Betik and Hepple 2008), and changes in body composition (Kuk et al. 2009) ultimately lead to a reduction in maximum oxygen consumption $\left(\mathrm{VO}_{2} \mathrm{max}\right)$ (approximately $1 \%$ decline per year post 25 years) (Lambert and Evans 2005). $\mathrm{VO}_{2} \max$ (or surrogate measures of $\mathrm{VO}_{2}$ max) correlate highly with mortality risk (Lee et al. 1999; Lee et al. 2010; Lee et al. 2011). These metabolic changes lead to a redistribution of nutrients, causing inappropriate fat deposition, which has been linked with systemic age related insulin resistance (Wolfe 2006).

Musculoskeletal deterioration in old age has severe health consequences. Skeletal muscle and the extracellular matrix of skeletal tendon-bone are essential for maintaining tissue structure and vital for muscular contraction and force transmission. Given the close link between muscle loss (sarcopenia) and bone loss (osteopenia), factors that affect muscle anabolism are also likely to effect bone mass. With advancing age, sarcopenia and osteopenia present major clinical problems, such as impaired locomotory function, compromised balance, increased risk of osteoarthritis and fall/fractures; all of which diminish quality of life in seniors (Cruz-Jentoft et al. 2010; Janssen et al. 2002; Landi et al. 2012a, b; Panel on Prevention of Falls in Older Persons and British Geriatrics 2011).

Even in conditions of 'healthy' ageing, there is a progressive decline in skeletal muscle quality as described by various changes in structure, mechanics and function. Lexell (1995) observed that males aged 15-83 years displayed an age-related reduction in muscle cross sectional area progressing after 25 years (Fig. 1a). This was primarily caused by a loss in the number of fibres but also a reduction in relative crosssectional area, particularly of type II fibres (Fig. 1b). The loss in fibre number and preferential loss in type II fibres may be related to changes in innervation, as with increasing age comes a loss of innervation of muscle fibres and a progressive loss of alpha-motorneurons (Brown 1972; Tomlinson and Irving 1977; Einsiedel and Luff 1992). Following the loss of alpha motorneurons, muscle fibres may become reinnervated by surrounding neurones in a cycle of denervation and reinnervation via collateral reinnervation (Holloszy and Larsson 1995) which likely contributes to the loss of strength and muscle mass with age (Luff 1998). With less motor neurones, the number of muscle fibres per motor unit increases, resulting in larger, less differentiated motor units (Andersen 2003). The preferential loss in type II fibre cross-sectional area may partly explain why age-associated losses in muscle strength and power occur at a greater and disproportionate rate to losses in muscle mass (Macaluso and De Vito 2004) and why aged muscle tends to show exacerbated fatigue resistance (Avin and Law 2011). As well as the above, numerous other factors including a reduction in number of satellite cells (Kadi et al. 2004), a potential shift towards slow myosin isoforms (Gelfi et al. 2006) and shortening of sarcomere length (Narici et al. 2003) have all be suggested to contribute to a reduction in force generating capacity of muscle tissue with ageing. It is extremely concerning that due to a loss of muscle strength with age, 16-18\% of women and 8-10\% of men over aged 65 cannot lift a $10 \mathrm{lb}$ weight or kneel down (FIFoA-R 2008). This loss of muscle strength with ageing is known as dynapenia (Clark and Manini 2008), occurring 2-5 times faster rate than losses of muscle mass (Clark et al. 2006; Delmonico et al. 2009). The Health, Ageing and Body Composition study found that even gaining muscle mass with ageing does not entirely prevent ageing-related 
A

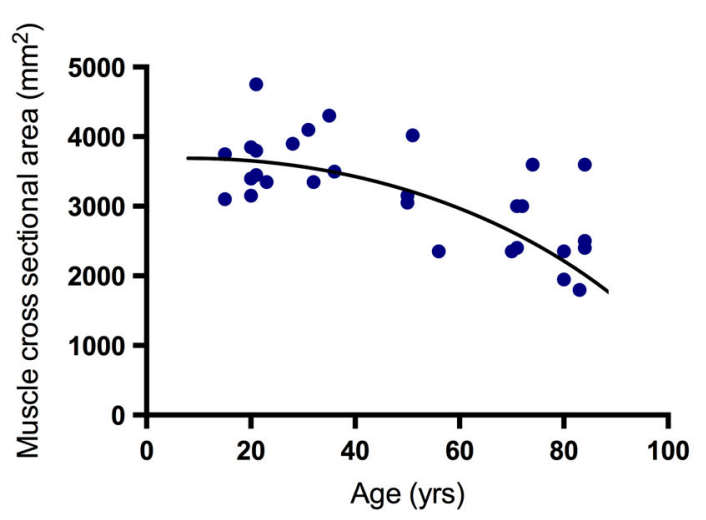

B

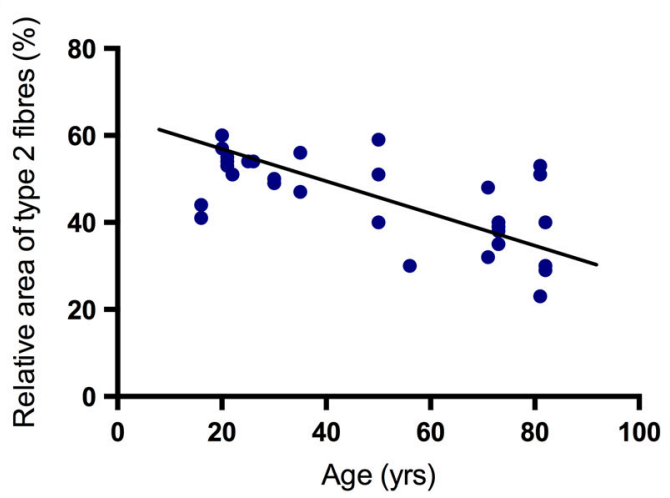

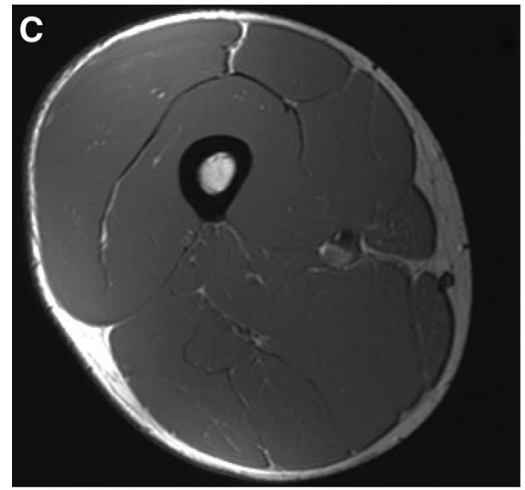

Male - 24 yrs

Body mass $-76 \mathrm{~kg}$

Fat mass $-10 \mathrm{~kg}$

Fat free mass $-57 \mathrm{~kg}$

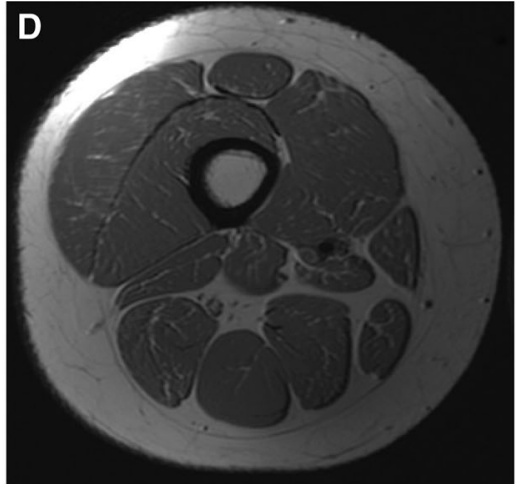

Male -66 yrs

Body mass $-81 \mathrm{~kg}$

Fat mass $-57 \mathrm{~kg}$

Fat free mass $-13 \mathrm{~kg}$

Average daily steps $=3141$

PA $>3$ MET per/day $=22$ mins

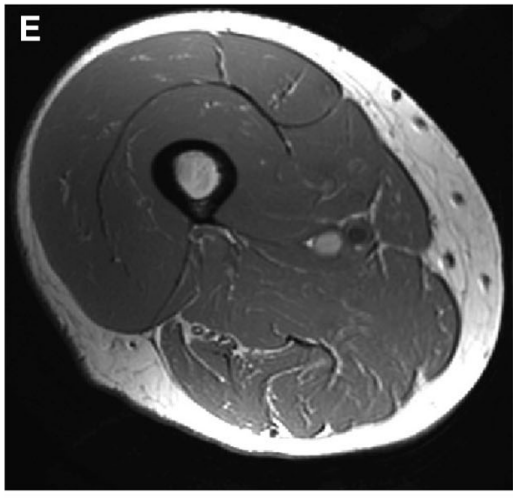

Male -66 yrs

Body mass $-79 \mathrm{~kg}$

Fat mass $-34 \mathrm{~kg}$

Fat free mass $-36 \mathrm{~kg}$

Average daily steps $=12445$

PA $>3$ MET per $/$ day $=130 \mathrm{mins}$
Fig. 1 Loss of skeletal muscle size and quality occurs during healthy ageing. Skeletal muscle cross sectional area (CSA) declines across lifespan (a) with a preferential decline observed in type 2 fibres (b). Representative MRI images depict skeletal

decreases in muscle strength (Delmonico et al. 2009). Infiltration of fat, and neural alterations are likely contributing factors, as well as changes in contractile properties (Kent-Braun et al. 2000), and many other mechanisms discussed elsewhere (Clark and Manini 2012; Mitchell et al. 2012). Dynapenia is a major risk factor for loss of dependence and mobility issues (Manini et al. 2007; Visser et al. 2005) as well as mortality (Newman et al. 2006; Takata et al. 2012).

Coupled to the loss of force generating capacity, there is a clear reduction of total muscle mass, at a rate of $\sim 4.7 \%$ peak mass/decade in men and $\sim 3.7 \%$ peak mass/decade in women (Mitchell et al. 2012). Graphical representation of this change in muscle size muscle architecture in young (c), old-inactive (d) and old-active (e) males. a and b are adapted from (Lexell 1995). Text represents subject characteristics relating to the images in $\mathbf{c}-\mathbf{e}$

and composition with age is illustrated in Fig. 1c-e (Breen et al. unpublished data). Image 1c shows an MRI scan from a young lean male, in contrast to an age-inactive (1D) and age-matched active individual (1E), with similar levels of dietary protein intake $[\sim 0.9 \mathrm{~g} /(\mathrm{kg} /$ body mass $)]$. Evident is the reduction in muscle mass with age (1C vs. 1D), the greater abundance and infiltration of fat around the muscle tissue (1C vs. 1D) and also the protective effect that maintained physical activity appears to have on skeletal muscle with ageing (1D vs. 1E). The accumulation of intramuscular fat may also be a key factor in the progressive mismatch between losses in mass and strength. Adipose tissue typically 
accumulates with age, producing numerous proinflammatory cytokines (adipokines) into the circulation which may accelerate muscle catabolism and contribute to a vicious cycle of muscle loss and fat accumulation (Schrager et al. 2007; Wellen and Hotamisligil 2003). Macrophage infiltration into the muscle as a result of increased lipid accumulation/ adipokine has been termed 'sarcopenic obesity' (Baumgartner 2000; Stenholm et al. 2008). The combination of lipotoxocity and inactivity/ageing has been proposed to reduce skeletal muscle anabolic responses to resistance exercise and nutrition (Murton et al. 2015; Nilsson et al. 2013; Sitnick et al. 2009; Stephens et al. 2015). Figure 1e illustrates the preservation of muscle mass and reduced fat infiltration from a 66-year-old male age matched to Fig. 1d. The only major difference found between individuals from 1D and $1 \mathrm{E}$ is the habitual physical activity levels, with $1 \mathrm{E}$ $\sim 4$ times more active than 1D. Therefore, physical activity levels (coupled with good dietary practice) can maintain muscle mass and also strength in old age.

\section{The importance of skeletal muscle strength for healthy ageing}

Ruiz et al. (2008) and coworkers carried out the most comprehensive study of its kind with over 8000 participants followed for approximately 18 years to assess the influence of muscle strength and cardiorespiratory fitness on healthy ageing (Ruiz et al. 2008).
Subjects underwent a rigorous set of strength tests and were stratified by strength (Fig. 2a-b). Remarkably, individuals over the age of 60 years, classified in the lowest third for strength, were $50 \%$ more likely to die of all cause mortality (Fig. 2a) than individuals in the upper third for strength (Ruiz et al. 2008). The same trend also applied when considering deaths associated with cancer (Fig. 2b), indicating that muscle strength, albeit correlative, has a protective effect from the incidence of cancer. A final key observation of this dataset was that regardless of strength, individuals with higher cardio-respiratory fitness had a greater life expectancy than low cardio-respiratory fitness counterparts (Fig. 2c). Collectively, this landmark study provided the first direct evidence that physical strength or the processes of developing strength is intrinsically linked to healthy ageing.

Muscle strength and $\mathrm{VO}_{2}$ max are likely great predictors for life span because they integrate both the neuromuscular and cardiovascular systems and as such indicate the health and functional integration of these tissues. As we have discussed, one of the key determinants of health span is muscle strength (and likely muscle mass), and one of the major key determinants of muscle mass retention is the ability to modify muscle protein synthesis in response to anabolic stimuli. Given the clear benefits of muscle strength and cardiovascular fitness on healthy ageing, the obvious question is what approaches can be taken to preserve muscle mass, strength and function across lifespan?

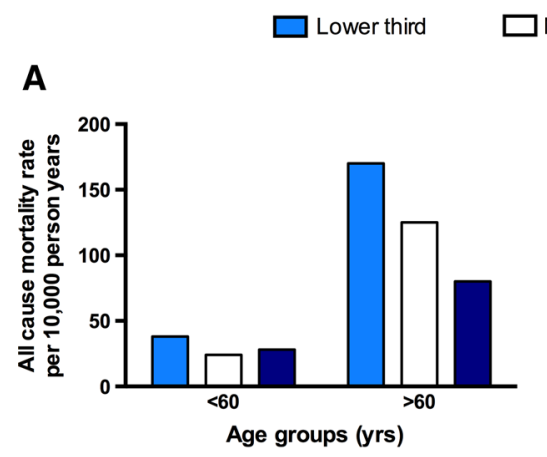

Fig. 2 Skeletal muscle strength and cardiorespiratory fitness is associated with healthy ageing. Over the age of 60 years, all cause (a) and cancer-associated (b) mortality is twice as likely in individuals with low compared to high skeletal muscle strength.
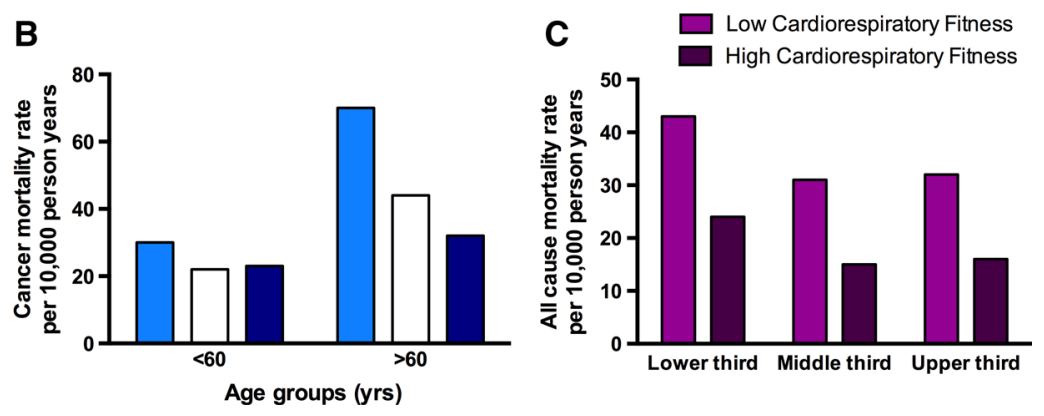

In addition, irrespective of strength, low cardio-respiratory fitness is associated with $\sim$ twice the incidence of all cause mortality (c). Adapted from (Ruiz et al. 2008) 
How is muscle mass, strength and function regulated at the molecular level?

The mechanistic target of rapamycin (mTOR) is a highly conserved serine/threonine kinase protein complex, identified as a central regulator of cellular growth (Fingar and Blenis 2004). Importantly, mTOR exists as 1 of 2 complexes and hyper-activity of the mTOR complexes 1 and 2 (mTORC1/2) has been implicated in tumor progression, pathological hypertrophy, diabetes and obesity (Lee et al. 2007; Sharp and Richardson 2011; Zoncu et al. 2011). mTORC1 and mTORC2 are very similar protein complexes differing in a few key subunits which alters kinase substrate preference. mTORC1 is the kinase component of both complexes and is a member of the phosphatidylinositol kinase (PIK) related kinases (Abraham 1996), although it does not possess lipid kinase activity (Brunn et al. 1997). The activity and substrate preference of mTOR is dependent upon several adapter proteins G $\beta$ L (Kim et al. 2003), raptor (Hara et al. 2002), rictor (Sarbassov et al. 2004), Sin1 (Yang et al. 2006) and Protor/PRR5 (Pearce et al. 2007; Woo et al. 2007), which form two separate mTOR complexes capable of regulating distinctive pathways. The mTOR complex 1 contains G $\beta \mathrm{L}$, raptor and $\mathrm{mTOR}$ and is rapamycin sensitive. G $\beta \mathrm{L}$ functions to stabilize the association between mTORC1 and raptor and enhances the kinase activity of mTORC1 towards its targets (Guertin et al. 2006), however is not essential for mTORC1 activity (Guertin et al. 2006). Raptor is an adapter protein that identifies and binds substrates that contain TOS (TOR signalling) motifs (Schalm et al. 2003) such as 4EBP and S6K1 (Schalm and Blenis 2002). mTORC 2 on the other hand consists of mTOR, rictor, G $\beta \mathrm{L}$, Sin1 and Protor/PRR5 and is rapamycin insensitive (Sarbassov et al. 2004).

mTORC1 regulates protein synthesis initiation by controlling the formation of the eIF4F complex (Gingras et al. 2004) and governs the pioneer round of mRNA translation by acting on SKAR via its putative target S6K1 (Ma et al. 2008). In addition, mTORC1 controls ribosomal biogenesis by regulating rDNA transcription in a manner dependant upon UBF (Hannan et al. 2003), and nuclear RNA export by regulating eIF4E in a manner dependant upon 4EBP1 phosphorylation (Culjkovic et al. 2005; Topisirovic et al. 2003; Topisirovic et al. 2004). In these roles mTORC1 is a critical regulator of protein synthesis and cell size (Fingar et al. 2002). It is well established that resistance exercise and provision of dietary protein activate mTORC1 synergistically, with the post exercise/post prandial activation of mTORC1 associated with increases in net protein synthesis in skeletal muscle (Brook et al. 2015).

The importance of exercise in the maintenance of muscle mass and function

There is increasing evidence that the trajectory of sarcopenia and muscle loss is highly dependent on physical activity levels (Kortebein et al. 2008). Chronic sedentary behaviour and physical inactivity are key mechanistic drivers of sarcopenia, and can accelerate loss of muscle mass and strength leading to impaired mobility, higher risk of falls and increased mortality (Montero-Fernandez and Serra-Rexach 2013). Even acute bouts of inactivity such as 10 days of bed rest in older adults can substantially reduce lower leg strength, reduce aerobic capacity by $12 \%$ and lead to a $7 \%$ reduction of physical activity after the bed rest programme (Kortebein et al. 2008). Pharmacological interventions aimed to slow the progression of, or reverse sarcopenia, have been generally unsuccessful (Borst 2004; Onder et al. 2009). Clear and effective lifestyle-based countermeasures are therefore needed.

Repeated resistance exercise results in muscle protein accretion (i.e. hypertrophy) through chronically elevated rates of synthesis that exceed that rate of breakdown (Brook et al. 2015; Wilkinson et al. 2014). However, the sarcopenic elderly demonstrate an agerelated anabolic resistance to exercise and protein ingestion (Cuthbertson et al. 2005; Kumar et al. 2009). Despite this anabolic resistance, the cumulative effects of chronic training with appropriate protein intake can promote muscle repair, muscle preservation and muscle growth in the elderly if a sufficient stimulus is maintained (Walker et al. 2011). In support of this, numerous studies have shown the beneficial effects of exercise in elderly individuals (Hakkinen et al. 1998) and even those aged $>90$ years (Fiatarone et al. 1994). Benefits include increased satellite cell content (Leenders et al. 2013) increased muscle cross-sectional area and myofiber differentiation (Kosek et al. 2006), increased muscle fibre size particularly in type II muscle fibers (Leenders et al. 2013) and greater muscle size and strength (Candow et al. 2006; 
Geirsdottir et al. 2012a). These are accompanied by metabolic adaptations such as increased metabolic rate (Hakkinen et al. 1998) mitochondrial biogenesis and efficiency of substrate metabolism (Holloszy and Coyle 1984???), and exercise capacity (McCartney et al. 1995). Long-term resistance training increases fibre dimension (Narici et al. 1996) strength and muscle function (Macaluso and De Vito 2004). Importantly, resistance exercise is also safe for use within the healthy elderly and possibly even in those with adverse cardiovascular signs or complications (Williams et al. 2007). In addition, resistance training has been observed to effectively improve balance (Orr et al. 2008) and in turn reduced fear of and occurrence of falling (Rubenstein et al. 2000), improve cognitive function (Cassilhas et al. 2007), decrease sit to stand time (Leenders et al. 2013), reduce risk of repeat and single hospitalisations (Lang et al. 2010) increase gait speed (Studenski et al. 2011) and most importantly improve overall quality of life (Geirsdottir et al. 2012b; Levinger et al. 2009). In addition, there is also growing evidence that the use of regular aerobic exercise can preserve muscle mass and function with age (Harber et al. 2009) a point we discuss in more detail in our recent review (Brook et al. 2015).

The importance of dietary protein

in the maintenance of muscle mass and function

Dietary protein is an essential macronutrient for the maintenance of muscle mass and function and, by close association, bone strength and density. The current recommended dietary allowance (RDA) for protein intake to meet whole-body metabolic demands is $0.8 \mathrm{~g} /(\mathrm{kg} /$ day) $(0.32 / \mathrm{kg} / \mathrm{LBM} /$ day if assuming LBM accounts for $40 \%$ of total body mass Janssen et al. 2000). However, the RDA does not distinguish between potential differences in the amount of protein required to maintain musculoskeletal health between young and older individuals. Given strong evidence that protein intakes greater than the current RDA are associated with multiple improved musculoskeletal health outcomes (Morley et al. 2010), it has been postulated that protein intakes should be defined in amounts that are 'optimal' to promote muscle/bone protein accretion, or at the very least, maintenance in old age.

Maintenance of musculoskeletal mass is dependent on nutrient-induced stimulation of muscle protein synthesis and the concomitant suppression of muscle protein breakdown to promote net protein accretion, which counters protein loss in the postabsorptive state. Protein-based nutrition robustly stimulates MPS through constituent essential amino acids (Chesley et al. 1992; Tipton et al. 1999). In particular, the branched-chain amino acid, leucine, displays potent muscle anabolic properties, and is capable of stimulating MPS and associated mTOR-mediated signaling in the absence of, and to a greater extent than, the other essential amino acids (Atherton et al. 2010; Wilkinson et al. 2013). The anabolic response of muscle to amino acid provision is relatively short lived, peaking at $\sim 2 \mathrm{~h}$ after protein ingestion, returning to postabsorptive values by $\sim 3 \mathrm{~h}$ after protein ingestion (Burd et al. 2010; Mitchell et al. 2015), even in situations where circulating amino acids remain elevated (Bohé et al. 2001).

A number of studies demonstrate that the muscle protein synthetic response to oral protein ingestion or essential amino acid infusion (to bypass potential agerelated differences in splanchnic extraction) is markedly lower in the old compared with the young (Cuthbertson et al. 2005; Guillet et al. 2004; Katsanos et al. 2005; Volpi et al. 2000). However, it is important to note that not all studies have been able to detect the presence of age-related muscle anabolic resistance to protein-based nutrition (Paddon-Jones et al. 2004; Pennings et al. 2011), perhaps due to differences in the methods used for assessment of MPS between studies (Burd et al. 2012). Mechanisms beyond the intramuscular level may also underpin the compromised muscle anabolic response to protein nutrition in older individuals. In this regard, it has been demonstrated that ageing is associated with greater splanchnic extraction of amino acids, thereby reducing the appearance of dietary protein (Volpi et al. 1999). Beyond this, others report that microvascular perfusion following nutrient provision is impaired in older individuals (Mitchell et al. 2013), which in theory may limit the capacity for EAA delivery and uptake into muscle.

A recently published study shed important light on the debate of whether 'anabolic resistance' resides in old age, Moore et al. (2015) and colleagues performed a retrospective analysis of studies from a large cohort of young and old individuals in which MPS was measured following ingestion of varying amounts of high quality protein. The authors demonstrated that the 
minimal amount of protein required to reach a maximal MPS response was $0.25 \mathrm{~g} / \mathrm{kg} / \mathrm{lean}$ body mass (LBM) in young individuals and $0.61 \mathrm{~g} / \mathrm{kg} / \mathrm{LBM}$ in the old, thus highlighting the older individuals are less sensitive to low protein intakes, and therefore have a greater relative protein requirement than the young (Fig. 3). These data are all the more concerning when one considers that many older individuals do not meet the current RDA for protein due to factors including anorexia, appetite loss, blunted olfactory perception, gastrointestinal issues and, in some cases, socioeconomic factors. On top of these concerning issues, many older individuals consume dietary protein in a skewed pattern (Tieland et al. 2012). For example, protein intake at breakfast and lunch is often suboptimal to maximally stimulate MPS $(<0.61 \mathrm{~g} / \mathrm{kg} /$ LBM), a response that may only be achieved when large-dose protein is consumed with dinner (Tieland et al. 2012). Collectively, these data have led to suggestions that protein intake should perhaps be distributed evenly across each meal.

The presence of muscle anabolic resistance in old age has led to calls for the protein RDA to be increased in this population in order to maximally stimulate MPS and, perhaps, alleviate the progression of sarcopenia. Considering the data presented by Moore et al. (2015), a 70 year old individual weighing $80 \mathrm{~kg}$ (assuming LBM accounts for $30 \%$ of total body mass (i.e. $24 \mathrm{~kg}$ ) and three square meals per day (Short and Nair 2000)) would need to consume $\sim 147 \mathrm{~g}$ of protein per day or $\sim 1.8 \mathrm{~g} / \mathrm{kg}$, more than twice the current RDA. In support of this hypothetical scenario, Kim et al. (2015) recently demonstrated that consuming $1.5 \mathrm{~g} /(\mathrm{kg} / \mathrm{body}$ mass $)$ of protein [almost double the

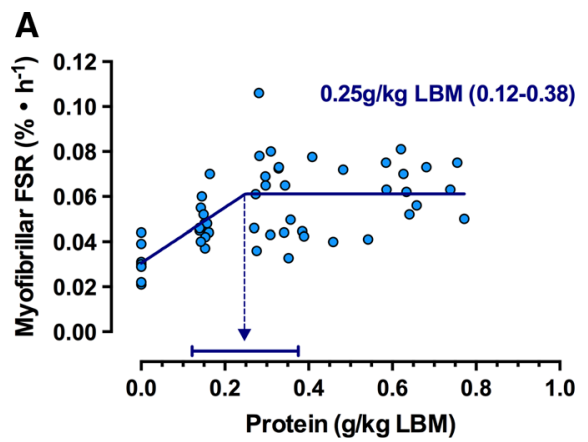

Fig. 3 Ageing is associated with a blunted anabolic response to protein ingestion in humans. Comparative analysis indicates that the protein dose required to maximally stimulate myofibrillar current $\mathrm{RDA}-0.8 \mathrm{~g} /(\mathrm{kg} /$ body mass $)$ ] resulted in markedly greater stimulation of MPS over $24 \mathrm{~h}$ compared with $0.8 \mathrm{~g} /(\mathrm{kg} / \mathrm{body}$ mass $)$ of protein. In this study, no added muscle anabolic benefit was reported when protein was ingested evenly as compared with skewed distribution (Kim et al. 2015). Beyond acute studies of MPS, long-term investigations also lend weight to the suggestion that the current RDA for protein is inadequate to meet the metabolic needs of older individuals. For example, Campbell et al. (2001) demonstrated that older individuals consuming the recommended protein RDA for 14 weeks experienced a significant loss in mid-thigh muscle area. In addition, data from the Health ABC study highlighted that older individuals in the highest quintile for protein intake ( $\sim 19 \%$ of total energy intake) lost $\sim 40 \%$ less lean mass than did those in the lowest quintile for protein intake $(\sim 11 \%$ of total energy intake) (Anderson et al. 2011).

It is clear that many older individuals do not consume sufficient protein to maintain whole-body and tissue-specific metabolic health, a situation that is worsened during periods of ill health and disability (Covinsky et al. 1999). Malnourishment during acute and chronic disease slows the rate of recovery, increases the risk of complications and re-admittance to hospital (Covinsky et al. 1999). Musculoskeletal unloading during illness and hospitalization occurs with greater frequency in older individuals and has dire consequences for musculoskeletal health. For example, it has been demonstrated that 7 days of bed rest induces muscle atrophy and anabolic resistance in older individuals (Drummond et al. 2012). Furthermore, we observed a similar loss in muscle

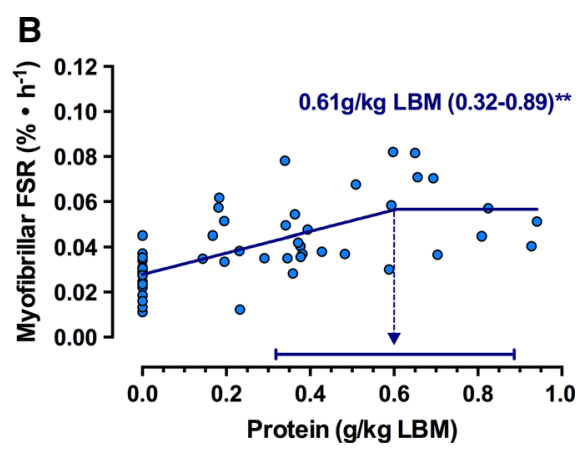

fractional protein synthesis rates in young individuals (a) is $40 \%$ lower than in old individuals (b). Data adapted from (Moore et al. 2015) 
mass and anabolic sensitivity in older individuals following 14 days of reduced ambulation (Breen et al. 2013). In addition to skeletal muscle defects, disuse events are also accompanied by severe osteopenia. Thus, deterioration in muscle anabolic responsiveness and bone properties during consecutive disuse events in old age may accumulate and drive the progression of sarcopenia and osteopenia. A general consensus gathering momentum is that high protein intakes (greater than the current RDA) are required during illness and hospitalization to maintain musculoskeletal health and quicken the rate of recovery (Cawood et al. 2012). This point is reinforced by evidence that muscle wasting is evident during disuse even with protein intakes of 1.0-1.2 g/(kg/body mass) (Trappe et al. 2007). From a clinical perspective, one study also reported that the sickest older hospital patients are the most protein malnourished (Pichard et al. 2004). Beyond skeletal muscle health, in osteoporosis there is evidence that higher bone mineral density is evident when protein intake exceeds the current RDA (Devine et al. 2005; Meng et al. 2009). Further, in hip fracture patients, supplemental or higher protein intakes (greater than the current RDA) are associated with increased bone density and a reduction in recovery time (Schurch et al. 1998). The notion that higher dietary protein intakes (particularly those high in sulphur-containing amino acids) may lead to blood acidification, calcium resorption from bones and osteoporosis (the so called 'acid-ash hypothesis) has been roundly disregarded in several metaanalyses (Fenton et al. 2008; Fenton et al. 2010; Fenton et al. 2009a; Fenton et al. 2009b). Specifically, it is clear that the available evidence does not support a causal association between dietary acid load and osteoporotic bone disease. To summarize, there is a clear need for dietary protein intake above the current RDA in older individuals to maintain musculoskeletal health and quality of life, with experts recommending between 1.0 and $1.2 \mathrm{~g} /$ ( $\mathrm{kg}$ body mass) for healthy older individuals (Bauer et al. 2013). Moreover, this need is likely to be increased further during periods where musculoskeletal mass is compromised, such as illness and hospitalization, with experts recommending between 1.2 and $2.0 \mathrm{~g} /(\mathrm{kg} /$ body mass $)$ in such situations (dependent on the severity of illness and extent of malnutrition) (Bauer et al. 2013).
Should research focus be on improving lifespan or healthspan?

Based on the data discussed above, it seems clear that skeletal muscle mass and strength is vital for healthy ageing, and that exercise and dietary protein are key mediators of mTORC1-accociated increases in skeletal muscle protein synthesis. However, there is a large body of evidence in model organisms suggesting that strategies that blunt protein synthesis (mTORC1 inhibition, calorie restriction) increase lifespan and as such show promise as longevity promoting therapies (Kapahi et al. 2010).

For example, the mTORC1 inhibitor Rapamycin increases lifespan in a variety of models including yeast (Kaeberlein et al. 2005), c. elegans (Jia et al. 2004) and Drosophila Melanogaster (Kapahi et al. 2004). In mice, Rapamycin increases lifespan at $90 \%$ mortality by $14 \%$ for males and $9 \%$ for females respectively, with survival increasing regardless of late-life (600 days of age) or mid-life (270 days of age) administration (Harrison et al. 2009). Consistent with the notion that reducing protein synthesis can increase lifespan, individually knocking out eIF4G and S6K1 (Selman et al. 2009) improves longevity in model organisms whilst individuals with mutations leading to low insulin like growth factor1 (IGF1) and insulin levels, key drivers of mTORC1 activity and protein synthesis during development, have reduced rates of cancer and diabetes (Guevara-Aguirre et al. 2011; Shevah and Laron 2007). Additionally, the offspring of centenarians (who have a delayed risk of developing certain diseases and an increased longevity against age matched controls) have low circulating IGF1 bioactivity (Vitale et al. 2012).

Some of the nuances in these various models/ studies have recently been expertly reviewed elsewhere (Sharples et al. 2015), and what is clearly apparent is that few studies have taken into account muscle strength, size and functional capacity when considering improvements in lifespan. As such, the physiological context (i.e. healthspan vs lifespan) of living longer in these models is often overlooked. Two key studies from Blake Rasmussen's lab; Dickinson et al. (2011) and Drummond et al. (2009) have experimentally tested the direct effect of rapamycin in human skeletal muscle (Fig. 4). First, Drummond et al. (2009), demonstrated that pretreatment of human subjects with rapamycin completely blocked the 


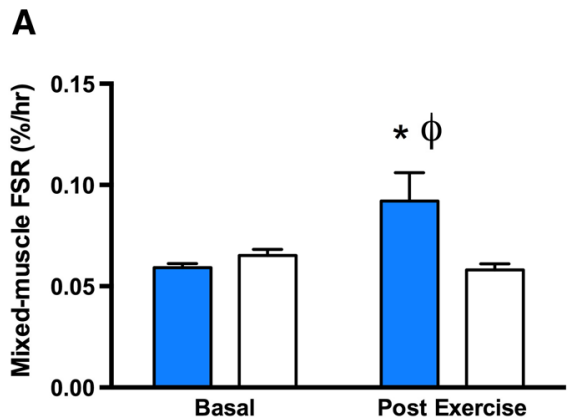

Fig. 4 Inhibition of mTORC1 activity using the compound Rapamycin causes anabolic resistance in young, healthy males. Increases in mixed-muscle synthesis rates are blocked following

ability of resistance exercise to increase muscle protein synthesis (Fig. 4a) confirming previous reports in rat skeletal muscle (Kubica et al. 2005). Second, Dickinson et al. (2011), demonstrates that rapamycin could completely block the muscle protein synthetic response to essential amino acids (Fig. 4b). Whilst no studies have examined the long-term effects of rapamycin treatment on skeletal muscle in humans, mice on chronic rapamycin supplementation display reduced myofibrillar protein synthesis (Drake et al. 2013) and loose the ability to accrue muscle mass following synergist ablation (Bodine et al. 2001). So effectively, rapamycin is inducing anabolic resistance in young, healthy individuals. Therefore rapamycin treatment in old individuals, already displaying anabolic resistance and frailty appears to be a questionable therapeutic approach to improve healthspan.

With regard to calorie restriction, it also seems clear that the severity of calorie restriction employed and the macronutrient content administered has a dramatic effect on the preservation or loss of muscle mass (Cerqueira and Kowaltowski 2010). For example, there is some evidence that supplementing protein during periods of negative energy balance can preserve muscle mass in healthy human volunteers, compared to energy restriction alone (Josse et al. 2011; Mettler et al. 2010; Phillips 2014). Therefore, it would appear that future research into the macronutrient content of calorie restricted diets, in combination with greater understanding of skeletal muscle function is an important future direction for calorie restriction research.

A final point of consideration is that longevity studies in rodents are conducted in thermo-neutral,

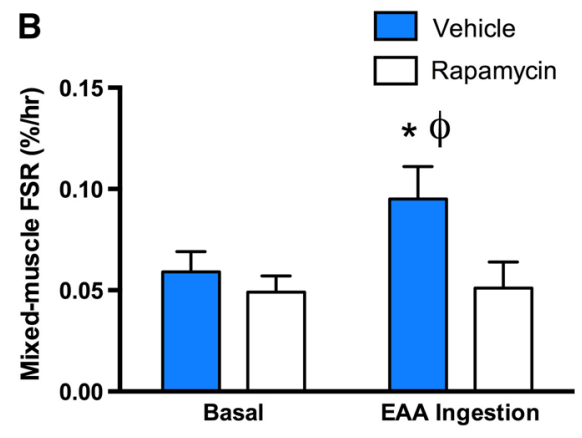

resistance exercise (a) and essential amino acid (EAA) ingestion (b) in young healthy males. a Adapted from (Drummond et al. 2009); b Adapted from (Dickinson et al. 2011)

pathogen free environments, in conditions where food and water are abundant. Rodents are not required to forage for food and compete with littermates for survival (both processes that require functional skeletal muscle). In fact a recent report suggests that mice housed in such conditions have poor health and functional capacity (Martin et al. 2010). In such situations, loss of muscle mass and physiological function is not a detrimental factor. Collectively, this therefore raises the important question as to what we are striving for in this area of biogerontology? Are we looking to increase lifespan at a compromise of healthspan, or would we rather live a healthy active life that encompasses maintenance of muscle mass, strength and function?

\section{Live strong and prosper}

If we return to the data from Ruiz et al. (2008), this would suggest that maintaining physical strength is a key strategy that leads to healthy ageing. Couple this with the numerous pre-clinical and clinical human studies we have discussed, and it seems clear that an active lifestyle supported by appropriate dietary protein is the key to maintaining strong, healthy skeletal muscle. In this context, the importance of muscle size and strength for longevity and health in humans puts a new spin on the Darwinian statement "Survival of the Fittest" as it is clear that the strongest, fittest individuals are more likely to live longer and healthier lives (Artero et al. 2011; Artero et al.; Haskell et al. 2007; Ruiz et al. 2009; Ruiz et al. 2008). Given the highlighted importance of muscle function for healthspan, it is hoped that all future age-related 
research will consider skeletal muscle during experimental interventions and strive to use readouts of function as the principal outputs as opposed to isolated gene or protein analysis. Finally, and perhaps most importantly, when it comes to fully understanding the complexities of human ageing, it is clear that the only way to really achieve clarity is through integrative studies, from basic model systems through to complimentary detailed clinical studies in humans.

Acknowledgments This publication was supported by a $\mathrm{PhD}$ studentship from the Biotechnology and Biological Sciences Research Council (BBSRC) funded Midlands Integrative Biosciences Training Program (MIBTP) to MM and a BBSRC New Investigator Award BB/L023547/1 to AP.

Open Access This article is distributed under the terms of the Creative Commons Attribution 4.0 International License (http:// creativecommons.org/licenses/by/4.0/), which permits unrestricted use, distribution, and reproduction in any medium, provided you give appropriate credit to the original author(s) and the source, provide a link to the Creative Commons license, and indicate if changes were made.

\section{References}

Abraham RT (1996) Phosphatidylinositol 3-kinase related kinases. Curr Opin Immunol 8:412-418

Andersen JL (2003) Muscle fibre type adaptation in the elderly human muscle. Scand J Med Sci Sports 13:40-47

Anderson AL et al (2011) Dietary patterns and survival of older adults. J Am Diet Assoc 111:84-91

Atherton PJ, Smith K, Etheridge T, Rankin D, Rennie MJ (2010) Distinct anabolic signalling responses to amino acids in C2C12 skeletal muscle cells. Amino Acids 38:1533-1539

Avin KG, Law LA (2011) Age-related differences in muscle fatigue vary by contraction type: a meta-analysis. Phys Ther 91:1153-1165. doi:10.2522/ptj.20100333

Bauer J et al (2013) Evidence-based recommendations for optimal dietary protein intake in older people: a position paper from the PROT-AGE Study Group. J Am Med Dir Assoc 14:542-559

Baumgartner R (2000) Body composition in healthy aging. Ann N Y Acad Sci 904:437-448

Baumgartner RN et al (1998) Epidemiology of sarcopenia among the elderly in New Mexico. Am $\mathrm{J}$ Epidemiol 147:755-763

Betik AC, Hepple RT (2008) Determinants of VO2 max decline with aging: an integrated perspective applied physiology, nutrition, and metabolism. Physiol Appl Nutr Metab 33:130-140. doi:10.1139/H07-174

Bodine SC et al (2001) Akt/mTOR pathway is a crucial regulator of skeletal muscle hypertrophy and can prevent muscle atrophy in vivo. Nat Cell Biol 3:1014-1019. doi:10. 1038/ncb1101-1014
Bohé J, Low J, Wolfe RR, Rennie MJ (2001) Rapid report. J Physiol 532:575-579

Borst SE (2004) Interventions for sarcopenia and muscle weakness in older people. Age Ageing 33:548-555. doi:10. 1093/ageing/afh201

Breen L et al (2013) Two weeks of reduced activity decreases leg lean mass and induces "anabolic resistance" of myofibrillar protein synthesis in healthy elderly. J Clin Endocrinol Metab 98:2604-2612

Brook MS, Wilkinson DJ, Phillips BE, Perez-Schindler J, Philp A, Smith K, Atherton PJ (2015) Skeletal muscle homeostasis and plasticity in youth and ageing: impact of nutrition and exercise. Acta Physiol. doi:10.1111/apha. 12532

Brown W (1972) A method for estimating the number of motor units in thenar muscles and the changes in motor unit count with ageing. J Neurol Neurosurg Psychiatry 35:845-852

Brunn GJ, Fadden P, Haystead TA, Lawrence JC Jr (1997) The mammalian target of rapamycin phosphorylates sites having a (Ser/Thr)-Pro motif and is activated by antibodies to a region near its $\mathrm{COOH}$ terminus. $\mathrm{J}$ Biol Chem 272:32547-32550

Burd NA et al (2010) Low-load high volume resistance exercise stimulates muscle protein synthesis more than high-load low volume resistance exercise in young men. PloS One 5:e12033

Burd NA, Wall BT, van Loon LJ (2012) The curious case of anabolic resistance: old wives' tales or new fables? J Appl Physiol 112:1233-1235

Campbell WW, Trappe TA, Wolfe RR, Evans WJ (2001) The recommended dietary allowance for protein may not be adequate for older people to maintain skeletal muscle The. J Gerontol A Biol Sci Med Sci 56:M373-M380

Candow DG, Chilibeck PD, Facci M, Abeysekara S, Zello GA (2006) Protein supplementation before and after resistance training in older men. Eur J Appl Physiol 97:548-556

Cassilhas RC, Viana VA, Grassmann V, Santos RT, Santos RF, Tufik S, Mello MT (2007) The impact of resistance exercise on the cognitive function of the elderly. Med Sci Sports Exerc 39:1401

Cawood A, Elia M, Stratton R (2012) Systematic review and meta-analysis of the effects of high protein oral nutritional supplements. Ageing Res Rev 11:278-296

Cerqueira FM, Kowaltowski AJ (2010) Commonly adopted caloric restriction protocols often involve malnutrition. Ageing Res Rev 9:424-430. doi:10.1016/j.arr.2010.05.002

Chesley A, MacDougall J, Tarnopolsky M, Atkinson S, Smith K (1992) Changes in human muscle protein synthesis after resistance exercise. J Appl Physiol 73:1383-1388

Clark BC, Fernhall B, Ploutz-Snyder LL (2006) Adaptations in human neuromuscular function following prolonged unweighting: I. Skeletal muscle contractile properties and applied ischemia efficacy. J Appl Physiol 101:256-263

Clark BC, Manini TM (2008) Sarcopenia =/= dynapenia. J Gerontol A Biol Sci Med Sci 63:829-834

Clark BC, Manini TM (2012) What is dynapenia? Nutrition 28:495-503

Covinsky KE, Martin GE, Beyth RJ, Justice AC, Sehgal AR, Landefeld CS (1999) The relationship between clinical assessments of nutritional status and adverse outcomes in 
older hospitalized medical patients. J Am Geriatr Soc 47:532-538

Cruz-Jentoft AJ et al (2010) Sarcopenia: European consensus on definition and diagnosis: report of the European working group on sarcopenia in older people. Age Ageing 39:412-423. doi:10.1093/ageing/afq034

Culjkovic B, Topisirovic I, Skrabanek L, Ruiz-Gutierrez M, Borden KL (2005) eIF4E promotes nuclear export of cyclin D1 mRNAs via an element in the 3'UTR. J Cell Biol 169:245-256

Cuthbertson D et al (2005) Anabolic signaling deficits underlie amino acid resistance of wasting, aging muscle. FASEB J 19:422-424

Delmonico MJ et al (2009) Longitudinal study of muscle strength, quality, and adipose tissue infiltration. Am J Clin Nutr 90:1579-1585. doi:10.3945/ajen.2009.28047

Devine A, Dick IM, Islam AF, Dhaliwal SS, Prince RL (2005) Protein consumption is an important predictor of lower limb bone mass in elderly women. Am J Clin Nutr 81:1423-1428

Dickinson JM et al (2011) Mammalian target of rapamycin complex 1 activation is required for the stimulation of human skeletal muscle protein synthesis by essential amino acids. J Nutr 141:856-862

Drake JC, Peelor FF, Biela LM, Watkins MK, Miller RA, Hamilton KL, Miller BF (2013) Assessment of mitochondrial biogenesis and mTORC1 signaling during chronic rapamycin feeding in male and female mice. J Gerontol A Biol Sci Med Sci 68:1493-1501

Drummond MJ et al (2009) Rapamycin administration in humans blocks the contraction-induced increase in skeletal muscle protein synthesis. J Physiol 587:1535-1546. doi:10. 1113/jphysiol.2008.163816

Drummond MJ et al (2012) Bed rest impairs skeletal muscle amino acid transporter expression, mTORC1 signaling, and protein synthesis in response to essential amino acids in older adults. Am $\mathbf{J}$ Physiol Endocrinol Metab 302:E1113-E1122

Einsiedel L, Luff A (1992) Alterations in the contractile properties of motor units within the ageing rat medial gastrocnemius. J Neurol Sci 112:170-177

Fenton TR, Eliasziw M, Lyon AW, Tough SC, Hanley DA (2008) Meta-analysis of the quantity of calcium excretion associated with the net acid excretion of the modern diet under the acid-ash diet hypothesis. Am J Clin Nutr 88:1159-1166

Fenton TR, Eliasziw M, Tough SC, Lyon AW, Brown JP, Hanley DA (2010) Low urine $\mathrm{pH}$ and acid excretion do not predict bone fractures or the loss of bone mineral density: a prospective cohort study. BMC Musculoskelet Disord 11:88. doi:10.1186/1471-2474-11-88

Fenton TR, Lyon AW, Eliasziw M, Tough SC, Hanley DA (2009a) Meta-analysis of the effect of the acid-ash hypothesis of osteoporosis on calcium balance. J Bone Mineral Res 24:1835-1840. doi:10.1359/jbmr.090515

Fenton TR, Lyon AW, Eliasziw M, Tough SC, Hanley DA (2009b) Phosphate decreases urine calcium and increases calcium balance: a meta-analysis of the osteoporosis acid-ash diet hypothesis. Nutr J 8:41. doi:10.1186/1475-2891-8-41

Fiatarone MA et al (1994) Exercise training and nutritional supplementation for physical frailty in very elderly people. N Engl J Med 330:1769-1775
FIFoA-R (2008) Older Americans 2008: key indicators of wellbeing. Government Printing Office

Fingar DC, Blenis J (2004) Target of rapamycin (TOR): an integrator of nutrient and growth factor signals and coordinator of cell growth and cell cycle progression. Oncogene 23:3151-3171

Fingar DC, Salama S, Tsou C, Harlow E, Blenis J (2002) Mammalian cell size is controlled by mTOR and its downstream targets S6K1 and 4EBP1/eIF4E. Genes Dev 16:1472-1487

Geirsdottir O, Arnarson A, Briem K, Ramel A, Jonsson P, Thorsdottir I (2012a) Effect of 12-week resistance exercise program on body composition, muscle strength, physical function, and glucose metabolism in healthy, insulin-resistant, and diabetic elderly Icelanders. J Gerontol Ser 10:Agls096

Geirsdottir OG, Arnarson A, Briem K, Ramel A, Tomasson K, Jonsson P, Thorsdottir I (2012b) Physical function predicts improvement in quality of life in elderly Icelanders after 12 weeks of resistance exercise. J Nutr Health Aging 16:62-66

Gelfi C et al (2006) The human muscle proteome in aging. J Proteome Res 5:1344-1353

Gingras AC, Raught B, Sonenberg N (2004) mTOR signaling to translation. Curr Top Microbiol Immunol 279:169-197

Guertin DA et al (2006) Ablation in mice of the mTORC components raptor, rictor, or mLST8 reveals that mTORC2 is required for signaling to Akt-FOXO and PKCalpha, but not S6K1. Dev Cell 11:859-871

Guevara-Aguirre J et al (2011) Growth hormone receptor deficiency is associated with a major reduction in pro-aging signaling, cancer, and diabetes in humans. Sci Transl Med 3:70ra13-70ra13

Guillet $\mathrm{C}$ et al (2004) Impaired anabolic response of muscle protein synthesis is associated with S6K1 dysregulation in elderly humans. FASEB J 18:1586-1587

Hakkinen K et al (1998) Changes in muscle morphology, electromyographic activity, and force production characteristics during progressive strength training in young and older men. J Gerontol Ser A, Biol Sci Med Sci 53:B415B423

Hannan KM et al (2003) mTOR-dependent regulation of ribosomal gene transcription requires $\mathrm{S} 6 \mathrm{~K} 1$ and is mediated by phosphorylation of the carboxy-terminal activation domain of the nucleolar transcription factor UBF. Mol Cell Biol 23:8862-8877

Hara K et al (2002) Raptor, a binding partner of target of rapamycin (TOR), mediates TOR action. Cell 110:177-189

Harber MP, Konopka AR, Douglass MD, Minchev K, Kaminsky LA, Trappe TA, Trappe S (2009) Aerobic exercise training improves whole muscle and single myofiber size and function in older women. Am J Physiol Regul Integr Comp Physiol 297:R1452-1459. doi:10.1152/ajpregu.00354. 2009

Harrison DE et al (2009) Rapamycin fed late in life extends lifespan in genetically heterogeneous mice. Nature 460:392-395

Haskell W et al (2007) Physical Activity and Public Health: Updated Recommendation for Adults from the American College of Sports Medicine and the American Heart 
Association Medicine and Science in sports and exercise. Circulation 39:1423-1434

Holloszy JO, Coyle EF (1984) Adaptations of skeletal muscle to endurance exercise and their metabolic consequences. J Appl Physiol 56:831-838

Holloszy JO, Larsson L (1995) Motor units: remodeling in aged animals The. J Gerontol A Biol Sci Med Sci 50:91-95

Janssen I, Heymsfield SB, Ross R (2002) Low relative skeletal muscle mass (sarcopenia) in older persons is associated with functional impairment and physical disability. J Am Geriatr Soc 50:889-896

Janssen I, Heymsfield SB, Wang ZM, Ross R (2000) Skeletal muscle mass and distribution in 468 men and women aged 18-88 yr. J Appl Physiol 89:81-88

Jia K, Chen D, Riddle DL (2004) The TOR pathway interacts with the insulin signaling pathway to regulate C. elegans larval development, metabolism and life span. Development (Cambridge, England) 131:3897-3906. doi:10.1242/ dev. 01255

Josse AR, Atkinson SA, Tarnopolsky MA, Phillips SM (2011) Increased consumption of dairy foods and protein during diet- and exercise-induced weight loss promotes fat mass loss and lean mass gain in overweight and obese premenopausal women. J Nutr 141:1626-1634. doi:10.3945/ jn.111.141028

Kadi F, Charifi N, Denis C, Lexell J (2004) Satellite cells and myonuclei in young and elderly women and men Muscle \& nerve 29:120-127

Kaeberlein M et al (2005) Regulation of yeast replicative life span by TOR and Sch9 in response to nutrients. Science (New York, NY) 310:1193-1196

Kapahi P, Chen D, Rogers AN, Katewa SD, Li PW-L, Thomas EL, Kockel L (2010) With TOR, less is more: a key role for the conserved nutrient-sensing TOR pathway in aging. Cell Metab 11:453-465

Kapahi P, Zid BM, Harper T, Koslover D, Sapin V, Benzer S (2004) Regulation of Lifespan in $<\mathrm{i}>$ Drosophila $</$ $\mathrm{i}>$ by Modulation of Genes in the TOR Signaling Pathway. Curr Biol 14:885-890

Katsanos CS, Kobayashi H, Sheffield-Moore M, Aarsland A, Wolfe RR (2005) Aging is associated with diminished accretion of muscle proteins after the ingestion of a small bolus of essential amino acids. Am J Clin Nutr 82:1065-1073

Kent-Braun JA, Ng AV, Young K (2000) Skeletal muscle contractile and noncontractile components in young and older women and men. J Appl Physiol 88:662-668

Kim DH et al (2003) GbetaL, a positive regulator of the rapamycin-sensitive pathway required for the nutrient-sensitive interaction between raptor and mTOR. Mol Cell 11:895-904

Kim I-Y et al (2015) Quantity of dietary protein intake, but not pattern of intake, affects net protein balance primarily through differences in protein synthesis in older adults. Am J Physiol Endocrinol Metab 308:E21-E28

Kortebein P et al (2008) Functional impact of 10 days of bed rest in healthy older adults. J Gerontol Ser A, Biol Sci Med Sci 63:1076-1081

Kosek DJ, Kim JS, Petrella JK, Cross JM, Bamman MM (2006) Efficacy of 3 days/wk resistance training on myofiber hypertrophy and myogenic mechanisms in young vs. older adults. J Appl Physiol (Bethesda, Md: 1985) 101:531-544

Kubica N, Bolster DR, Farrell PA, Kimball SR, Jefferson LS (2005) Resistance exercise increases muscle protein synthesis and translation of eukaryotic initiation factor 2Bepsilon mRNA in a mammalian target of rapamycindependent manner. J Biol Chem 280:7570-7580

Kuk JL, Saunders TJ, Davidson LE, Ross R (2009) Age-related changes in total and regional fat distribution. Ageing Res Rev 8:339-348. doi:10.1016/j.arr.2009.06.001

Kumar V et al (2009) Age-related differences in the dose-response relationship of muscle protein synthesis to resistance exercise in young and old men. J Physiol 587:211-217

Lambert CP, Evans WJ (2005) Adaptations to aerobic and resistance exercise in the elderly. Rev Endocr Metab Disord 6:137-143. doi:10.1007/s11154-005-6726-5

Landi F et al (2012a) Sarcopenia and mortality among older nursing home residents. J Am Med Dir Assoc 13:121-126. doi:10.1016/j.jamda.2011.07.004

Landi F et al (2012b) Sarcopenia as a risk factor for falls in elderly individuals: results from the ilSIRENTE study. Clin Nutr 31:652-658. doi:10.1016/j.clnu.2012.02.007

Lang T, Streeper T, Cawthon P, Baldwin K, Taaffe DR, Harris TB (2010) Sarcopenia: etiology, clinical consequences, intervention, and assessment. Osteoporos Int 21:543-559

Lee CD, Blair SN, Jackson AS (1999) Cardiorespiratory fitness, body composition, and all-cause and cardiovascular disease mortality in men. Am J Clin Nutr 69:373-380

Lee CH, Inoki K, Guan KL (2007) mTOR pathway as a target in tissue hypertrophy. Annu Rev Pharmacol Toxicol 47:443-467

Lee DC, Artero EG, Sui X, Blair SN (2010) Mortality trends in the general population: the importance of cardiorespiratory fitness. J Psychopharmacol 24:27-35. doi:10.1177/ 1359786810382057

Lee DC et al (2011) Comparisons of leisure-time physical activity and cardiorespiratory fitness as predictors of allcause mortality in men and women. $\mathrm{Br} \mathrm{J}$ Sports Med 45:504-510. doi:10.1136/bjsm.2009.066209

Leenders M, Verdijk LB, van der Hoeven L, van Kranenburg J, Nilwik R, van Loon LJ (2013) Elderly men and women benefit equally from prolonged resistance-type exercise training The. J Gerontol A Biol Sci Med Sci 68:769-779

Levinger I, Goodman C, Hare DL, Jerums G, Selig S (2009) Functional capacity and quality of life in middle-age men and women with high and low number of metabolic risk factors. Int J Cardiol 133:281-283

Lexell J (1995) Human aging, muscle mass, and fiber type composition. J Gerontol Ser A, Biol Sci Med Sci 50(Spec No): $11-16$

Luff AR (1998) Age-associated changes in the innervation of muscle fibers and changes in the mechanical properties of motor units. Ann N Y Acad Sci 854:92-101

Ma XM, Yoon SO, Richardson CJ, Julich K, Blenis J (2008) SKAR links pre-mRNA splicing to mTOR/S6K1-mediated enhanced translation efficiency of spliced mRNAs. Cell 133:303-313. doi:10.1016/j.cell.2008.02.031

Macaluso A, De Vito G (2004) Muscle strength, power and adaptations to resistance training in older people. Eur $\mathrm{J}$ Appl Physiol 91:450-472 
Manini TM et al (2007) Knee extension strength cutpoints for maintaining mobility. J Am Geriatr Soc 55:451-457

Martin B, Ji S, Maudsley S, Mattson MP (2010) "Control" laboratory rodents are metabolically morbid: why it matters. Proc Natl Acad Sci 107:6127-6133

McCartney N, Hicks AL, Martin J, Webber CE (1995) Longterm resistance training in the elderly: effects on dynamic strength, exercise capacity, muscle, and bone. J Gerontol Ser A, Biol Sci Med Sci 50:B97-B104

Meng X, Zhu K, Devine A, Kerr DA, Binns CW, Prince RL (2009) A 5-year cohort study of the effects of high protein intake on lean mass and BMC in elderly postmenopausal women. J Bone Miner Res 24:1827-1834

Mettler S, Mitchell N, Tipton KD (2010) Increased protein intake reduces lean body mass loss during weight loss in athletes. Med Sci Sports Exerc 42:326-337. doi:10.1249/ MSS.0b013e3181b2ef8e

Mitchell WK, Phillips BE, Williams JP, Rankin D, Lund JN, Smith K, Atherton PJ (2015) A Dose-rather than Delivery Profile-Dependent Mechanism Regulates the "MuscleFull" Effect in Response to Oral Essential Amino Acid Intake in Young Men. J Nutr 145:207-214

Mitchell WK, Phillips BE, Williams JP, Rankin D, Smith K, Lund JN, Atherton PJ (2013) Development of a new Sonovue $^{\mathrm{TM}}$ contrast-enhanced ultrasound approach reveals temporal and age-related features of muscle microvascular responses to feeding. Physiol Rep 1:e00119

Mitchell WK, Williams J, Atherton P, Larvin M, Lund J, Narici M (2012) Sarcopenia, dynapenia, and the impact of advancing age on human skeletal muscle size and strength; a quantitative. Rev Front Physiol 3:260

Montero-Fernandez N, Serra-Rexach JA (2013) Role of exercise on sarcopenia in the elderly. Eur J Phys Rehabil Med 49:131-143

Moore DR, Churchward-Venne TA, Witard O, Breen L, Burd NA, Tipton KD, Phillips SM (2015) Protein ingestion to stimulate myofibrillar protein synthesis requires greater relative protein intakes in healthy older versus younger men. J Gerontol Ser A, Biol Sci Med Sci 70:57-62. doi:10. 1093/gerona/glu 103

Morley JE et al (2010) Nutritional recommendations for the management of sarcopenia. J Am Med Dir Assoc 11:391-396

Murton AJ, Marimuthu K, Mallinson JE, Selby AL, Smith K, Rennie MJ, Greenhaff PL (2015) Obesity appears to be associated with altered muscle protein synthetic and breakdown responses to increased nutrient delivery in older men, but not reduced muscle mass or contractile function. Diabetes 26: db150021

Narici MV et al (1996) Human quadriceps cross-sectional area, torque and neural activation during 6 months strength training. Acta Physiol Scand 157:175-186

Narici MV, Maganaris CN, Reeves ND, Capodaglio P (2003) Effect of aging on human muscle architecture. J Appl Physiol (Bethesda, Md: 1985) 95: 2229-2234 doi: 10.1152/ japplphysiol.00433.2003

Newman AB et al (2006) Strength, but not muscle mass, is associated with mortality in the health, aging and body composition study cohort. J Gerontol A Biol Sci Med Sci 61:72-77
Nilsson MI et al (2013) Abnormal protein turnover and anabolic resistance to exercise in sarcopenic obesity. FASEB J 27:3905-3916

Onder G, Della Vedova C, Landi F (2009) Validated treatments and therapeutics prospectives regarding pharmacological products for sarcopenia. JNHA: J Nutr Health Aging 13:746-756

Orr R, Raymond J, Singh MF (2008) Efficacy of progressive resistance training on balance performance in older adults. Sports Med 38:317-343

Paddon-Jones D et al (2004) Amino acid ingestion improves muscle protein synthesis in the young and elderly. Am J Physiol-Endocrinol Metab 286:E321-E328

Panel on Prevention of Falls in Older Persons AGS, British Geriatrics S (2011) Summary of the Updated American Geriatrics Society/British Geriatrics Society clinical practice guideline for prevention of falls in older persons. J Am Geriatr Soc 59:148-157. doi:10.1111/j.1532-5415.2010. 03234.x

Pearce LR et al (2007) Identification of Protor as a novel Rictorbinding component of mTOR complex-2. Biochem J 405:513-522

Pennings B, Koopman R, Beelen M, Senden JM, Saris WH, van Loon LJ (2011) Exercising before protein intake allows for greater use of dietary protein-derived amino acids for de novo muscle protein synthesis in both young and elderly men. Am J Clin Nutr 93:322-331

Phillips SM (2014) A brief review of higher dietary protein diets in weight loss: a focus on athletes. Sports Med 44(Suppl 2):S149-S153. doi:10.1007/s40279-014-0254-y

Pichard C, Kyle UG, Morabia A, Perrier A, Vermeulen B, Unger P (2004) Nutritional assessment: lean body mass depletion at hospital admission is associated with an increased length of stay. Am J Clin Nutr 79:613-618

Rosenberg IH (1989) Summary comments. Am J Clin Nutr 50:1231-1233

Rubenstein LZ, Josephson KR, Trueblood PR, Loy S, Harker JO, Pietruszka FM, Robbins AS (2000) Effects of a group exercise program on strength, mobility, and falls among fall-prone elderly men. J Gerontol Ser A, Biol Sci Med Sci 55:M317-M321

Ruiz JR et al (2009) Muscular strength and adiposity as predictors of adulthood cancer mortality in men Cancer epidemiology, biomarkers \& prevention : a publication of the American Association for Cancer Research, cosponsored by the American Society of Preventive. Oncology 18:1468-1476. doi:10.1158/1055-9965.EPI-08-1075

Ruiz JR, Sui X, Lobelo F, Morrow JR Jr, Jackson AW, Sjostrom M, Blair SN (2008) Association between muscular strength and mortality in men: prospective cohort study. Bmj 337:a439. doi:10.1136/bmj.a439

Sarbassov DD et al (2004) Rictor, a novel binding partner of mTOR, defines a rapamycin-insensitive and raptor-independent pathway that regulates the cytoskeleton. Curr Biol 14:1296-1302

Schalm SS, Blenis J (2002) Identification of a conserved motif required for mTOR signaling. Curr Biol 12:632-639

Schalm SS, Fingar DC, Sabatini DM, Blenis J (2003) TOS motif-mediated raptor binding regulates 4E-BP1 multisite phosphorylation and function. Curr Biol 13:797-806 
Schrager MA, Metter EJ, Simonsick E, Ble A, Bandinelli S, Lauretani F, Ferrucci L (2007) Sarcopenic obesity and inflammation in the InCHIANTI study. J Appl Physiol 102:919-925

Schurch M-A, Rizzoli R, Slosman D, Vadas L, Vergnaud P, Bonjour J-P (1998) Protein supplements increase serum insulin-like growth factor-I levels and attenuate proximal femur bone loss in patients with recent hip fracture: a randomized, double-blind, placebo-controlled trial. Ann Intern Med 128:801-809

Selman C et al (2009) Ribosomal protein S6 kinase 1 signaling regulates mammalian life span. Science 326:140-144

Sharp ZD, Richardson A (2011) Aging and cancer: can mTOR inhibitors kill two birds with one drug? Targ Oncol 6:41-51

Sharples AP, Hughes DC, Deane CS, Saini A, Selman C, Stewart CE (2015) Longevity and skeletal muscle mass: the role of IGF signalling, the sirtuins, dietary restriction and protein intake. Aging cell 14: 511-523

Shevah O, Laron Z (2007) Patients with congenital deficiency of IGF-I seem protected from the development of malignancies: a preliminary report. Growth Hormon IGF Res 17:54-57

Short KR, Nair KS (2000) The effect of age on protein metabolism. Curr Opin Clin Nutr Metab Care 3:39-44

Sitnick M, Bodine SC, Rutledge JC (2009) Chronic high fat feeding attenuates load-induced hypertrophy in mice. J Physiol 587:5753-5765

Stenholm S, Harris TB, Rantanen T, Visser M, Kritchevsky SB, Ferrucci L (2008) Sarcopenic obesity: definition, cause and consequences. Curr Opin Clin Nutr Metab Care 11:693-700. doi:10.1097/MCO.0b013e328312c37d

Stephens FB, Chee C, Wall BT, Murton AJ, Shannon CE, van Loon LJ, Tsintzas K (2015) Lipid-induced insulin resistance is associated with an impaired skeletal muscle protein synthetic response to amino acid ingestion in healthy young men. Diabetes 64:1615-1620

Studenski S et al (2011) Gait speed and survival in older adults. Jama 305:50-58

Takata Y et al (2012) Physical fitness and 6.5-year mortality in an 85-year-old community-dwelling population. Arch Gerontol Geriatr 54:28-33

Taylor BJ, Johnson BD (2010) The pulmonary circulation and exercise responses in the elderly. In: Seminars in respiratory and critical care medicine, vol 5. NIH Public Access, p 528

Tieland M, Borgonjen-Van den Berg KJ, van Loon LJ, de Groot LC (2012) Dietary protein intake in community-dwelling, frail, and institutionalized elderly people: scope for improvement. Eur J Nutr 51:173-179

Tipton KD, Ferrando AA, Phillips SM, Doyle D, Wolfe RR (1999) Postexercise net protein synthesis in human muscle from orally administered amino acids. Am J Physiol Endocrinol Metab 276:E628-E634

Tomlinson B, Irving D (1977) The numbers of limb motor neurons in the human lumbosacral cord throughout life. J Neurol Sci 34:213-219

Topinkova E (2008) Aging, disability and frailty Annals of nutrition \& metabolism 52 Suppl 1:6-11 doi: 10.1159/ 000115340

Topisirovic I, Culjkovic B, Cohen N, Perez JM, Skrabanek L, Borden KL (2003) The proline-rich homeodomain protein,
$\mathrm{PRH}$, is a tissue-specific inhibitor of eIF4E-dependent cyclin D1 mRNA transport and growth. EMBO J 22:689-703

Topisirovic I, Ruiz-Gutierrez M, Borden KL (2004) Phosphorylation of the eukaryotic translation initiation factor eIF4E contributes to its transformation and mRNA transport activities. Cancer Res 64:8639-8642

Trappe T, Burd N, Louis E, Lee G, Trappe S (2007) Influence of concurrent exercise or nutrition countermeasures on thigh and calf muscle size and function during 60 days of bed rest in women. Acta Physiol 191:147-159

Visser M et al (2005) Muscle mass, muscle strength, and muscle fat infiltration as predictors of incident mobility limitations in well-functioning older persons The. J Gerontol A Biol Sci Med Sci 60:324-333

Vitale $\mathrm{G}$ et al (2012) Low circulating IGF-I bioactivity is associated with human longevity: findings in centenarians' offspring. Aging (Albany NY) 4:580

Volpi E, Mittendorfer B, Rasmussen BB, Wolfe RR (2000) The response of muscle protein anabolism to combined hyperaminoacidemia and glucose-induced hyperinsulinemia is impaired in the elderly 1. J Clin Endocrinol Metab $85: 4481-4490$

Volpi E, Mittendorfer B, Wolf SE, Wolfe RR (1999) Oral amino acids stimulate muscle protein anabolism in the elderly despite higher first-pass splanchnic extraction. Am J Physiol-Endocrinol Metab 277:E513-E520

Walker DK et al (2011) Exercise, amino acids, and aging in the control of human muscle protein synthesis. Med Sci Sports Exerc 43:2249-2258. doi:10.1249/MSS.0b013e318223b037

Wellen KE, Hotamisligil GS (2003) Obesity-induced inflammatory changes in adipose tissue. J Clin Investig 112:1785

Wilkinson D et al (2013) Effects of leucine and its metabolite $\beta$ hydroxy- $\beta$-methylbutyrate on human skeletal muscle protein metabolism. J Physiol 591:2911-2923

Wilkinson DJ et al (2014) A validation of the application of $\mathrm{D}(2) \mathrm{O}$ stable isotope tracer techniques for monitoring dayto-day changes in muscle protein subfraction synthesis in humans. Am J Physiol Endocrinol Metab 306: E571-579 doi: 10.1152/ajpendo.00650.2013

Williams MA et al (2007) Resistance exercise in individuals with and without cardiovascular disease: 2007 update a scientific statement from the american heart association council on clinical cardiology and council on nutrition, physical activity, and metabolism. Circulation 116:572-584

Wolfe RR (2006) The underappreciated role of muscle in health and disease. Am J Clin Nutr 84:475-482

Woo SY et al (2007) PRR5, a novel component of mTOR complex 2, regulates platelet-derived growth factor receptor beta expression and signaling. J Biol Chem 282:25604-25612

Yang Q, Inoki K, Ikenoue T, Guan KL (2006) Identification of Sin1 as an essential TORC2 component required for complex formation and kinase activity. Genes Dev 20:2820-2832

Zoncu R, Efeyan A, Sabatini DM (2011) mTOR: from growth signal integration to cancer, diabetes and ageing. Nat Rev Mol Cell Biol 12:21-35 